\title{
MUSIC AS RULED BY PRIMARY PROCESSES: CONDENSATION
}

\section{Miloš Zatkalik}

\begin{abstract}
Of all the arts, music is the closest to primary processes and the archaic modes of mental functioning. Consequently, condensation as one of the basic primary process mechanisms plays an important role in music. It manifests as the condensation of different musical entities (themes, scales etc.), of different principles of organization, and also as an underlying logic of those analytic strategies that postulate the existence of structural layers, where events at deeper levels condense several more superficial events (e. g. Schenkerian analysis).
\end{abstract}

Keywords: psychoanalysis; condensation; Mokranjac; Schenkerian analysis.

Among Sigmund Freud's (1856-1939) numerous patients, few have earned such fame as Sergei Pankeiev, known as the Wolf Man. This moniker originates in the patient's childhood dream, analysed in detail in Freud's study From the History of an Infantile Neurosis (Freud, 1918). The dream was reported to Freud as follows:

"I dreamt that it was night and that I was lying in my bed. (My bed stood with its foot towards the window; in front of the window there was a row of old walnut trees. I know it was winter when I had the dream, and night-time.) Suddenly the window opened of its own accord, and I was terrified to see that some white wolves were sitting on the big walnut tree in front of the window. There were six or seven of them. The wolves were quite white, and looked more like foxes or sheepdogs, for they had big tails like foxes and they had their ears pricked like dogs when they pay attention to something. In great terror, evidently of being eaten up by the wolves, I screamed and woke up. It took quite a long while before I was convinced that it had only been a dream; I had had such a clear and life-like picture of the window opening and the wolves sitting on the tree. At last I grew quieter, felt as though I had escaped from some danger, and went to sleep again. The only piece of action in the dream was the opening of the window; for the wolves sat quite still and without making any movement on the branches of the tree. It seemed as though they had riveted their whole attention upon me." (Freud, 1918, 29)

Among psychoanalysts, it is widely accepted that the study of dreams is perhaps the most viable path towards the understanding of the unconscious mind - it is the royal road to the unconscious as Freud famously said. Namely, psychoanalysis teaches us that certain experiences, especially traumatic ones, are repressed into the unconscious, and it is in dreams that they reveal themselves most tellingly. Yet, in dreams they undergo certain transformations. From the study of this particular dream - and similar conclusion could be drawn if we were 
to study virtually any other dream - we learn that one of the dreamer's traumatic childhood experiences was associated with the figure of a wolf from his picture book. In the dream as retold by the patient, the wolf is multiplied into "six or seven of them". Fragments from different representations may be recombined. Thus, the patient's family raised sheep. One of their properties - their whiteness - is dissociated from them and displaced onto wolves, hence the wolves are white. Where there are sheep there are sheepdogs, so the wolves have "their ears pricked up like dogs", as the dreamer himself described. Another childhood memory was related to a story involving foxes, and the wolves' "tails are like foxes". It transpires that the wolves actually represent a condensed image of wolves, sheep, sheepdogs, and foxes. Condensation takes even further steps. Freud's analysis reveals that the patient has witnessed a sexual intercourse of his parents, experiencing it - as many children do - as an act of violence. This led to the repression of the scene into the unconscious, but the dream brought it back conflating the image of the father with the wolves. Furthermore, the wolves stare at the dreamer, which is actually the dreamer's own act of staring at his parents: the dreamer's stare is displaced onto the wolves, turned into its opposite. This account shows how latent, unconscious dream thoughts are represented by the manifest dream content. Dream work distorts images in order to make the repressed content acceptable for the dreamer, to pass the psychic censorship, as Freud called it.

Connections between various forms of artistic creation (and for that matter reception) and the unconscious mind are well documented. Among many artists who identified the most archaic layers of their psyche as the birth place of their creative impulses, Johannes Brahms (1833-1897) expressed this idea with extraordinary clarity (even if he could not possibly be aware of the technical vocabulary of psychoanalysis): "I am in a trance-like condition - hovering between being asleep and awake; I am still conscious but right on the border of losing consciousness and it is at such moments that inspired ideas come" (qtd. in Abel, 1955, 25).

Still more germane to my present topic is the fact that the transformations indicated in the above account of the "wolf dream" also govern a great deal of music. Over the last several years I have collaborated with Belgrade psychoanalyst Aleksandar Kontić and this resulted in several published papers and conference presentations. We have repeatedly argued that there exists a kind of isomorphism between musical structures and processes, and processes unfolding at the earliest stages of psychic development (Zatkalik and Kontić, 2013; 2015). The starting point for elucidating this isomorphism is the fact that we are born with the faculty of hearing and even with considerable prenatal auditory experience. Any such experience in the visual realm is utterly impossible. According to a model proposed by psychoanalytically oriented developmental psychology, at the earliest stages of individual development, the 
world is first represented through auditory images. Powerful primordial affects are associated precisely with sound imagery (Zatkalik and Kontić, 2015, 129, 140; cf. Stern, 1977; 1985). These early processes are known as primary: they are unconscious and pre-verbal; directed toward the subjective realm, seeking the immediate discharge of tension and having little reference to the exigencies of reality. Also, the earliest experience of a human individual is one of permeation between oneself and the environment: the lack of differentiation between $I$ and not-I ("oceanic feeling"). The role of sound in these early developmental stages merits our special attention. Sound is apparently (one of) the earliest sources of tension. It is also a means of communication between mother and baby, which, even if outwardly verbal, is based on the timbre, rhythm and intonation of the words (their "musical" aspects), rather than their semantic content. Sound can sustain such communication even when visual contact is broken, enabling the child to exert "magical control" over the mother at all times (could this be the origin of the belief in the magic power of music?).

Starting from this experience of being fused with the world, psychological development is characterized precisely by the evolving sense of self out of the primary mother-infant unity. Again, the role of sound must be emphasized. Namely, as the child becomes aware of the boundaries of the self, sound can function as what psychoanalyst Donald Winnicott called the transitional object, something which is $I$ and not $I$ at the same time (Winnicott, 1953). As we develop, our mental activities move from the primary processes towards the secondary ones, related to external reality, formal logic and verbal language. Very importantly, these new structures do not dissolve the archaic ones: they exist simultaneously. Our mind is capable of fluctuating between the two states in a manner that could be compared to a pendulum.

The paramount role of sound in the early infancy, and its connection with the affective world makes a strong case for the claim that an art realized in sound must bear powerful analogies with those archaic modes of mental functioning, enabling Arnold Schoenberg (1875-1951) to state that music is a language of the unconscious. It would, however, be more accurate to talk about isomorphism between primary psychic processes and the processes unfolding in music.

In the present paper I am focusing on the mechanism of condensation. According to a textbook definition, condensation is the representation of a chain of mental associations by a single idea (an image, memory, or thought), which appropriates the whole charge of libido of at least two other ideas. The charges are displaced from the originating ideas to the receiving one, where they condense together. One link takes the place of several chains, and this makes it more difficult to read through to the wish corresponding to those chains, since the wish may be unacceptable to the dreamer's superego. It thus, among other things, serves the interest of psychic censorship. 
Music's predilection for condensation is amazing. It affects all musical parameters, all aspects of music.

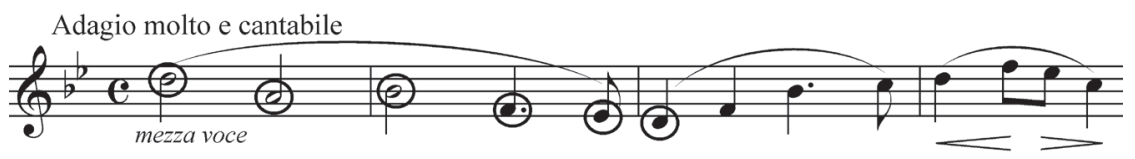

Figure 1a. L. v. Beethoven: Symphony No. 9, III movement, I theme

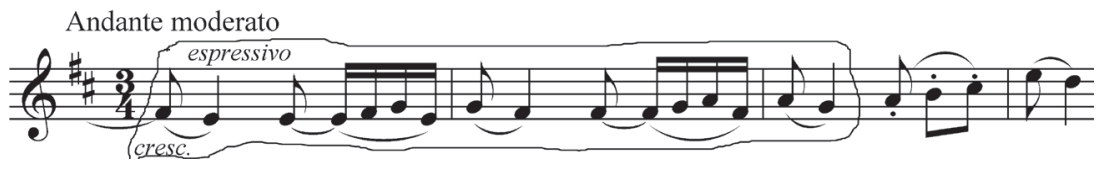

Figure 1b. L. v. Beethoven: Symphony No. 9, III movement, II theme

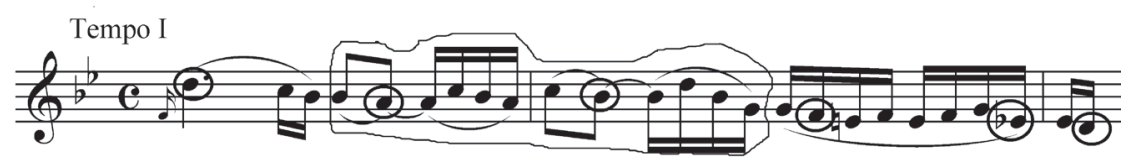

Figure 1c. L. v. Beethoven: Symphony No. 9, III movement, Variation on theme I (and II?)

Diverse thematic materials can be fused, as in the third movement of Ludwig van Beethoven's (1770-1827) Ninth Symphony. The form of this movement is variations on the two themes, and the above example reproduces the respective beginnings of the themes. When the first theme reappears in a varied form (Figure 1c), we not only recognize its melodic skeleton, we can also see how certain properties of the second theme are grafted onto it, as it were. The resulting entity merges some properties of both, in much the same way as the whiteness of sheep has been transferred to the wolves in the dream quoted at the beginning of this article.

Different modes or scales merge with one another, creating poly-modality such as frequently utilized by Béla Bartók (1881-1945). I am not talking merely about the use of different scales in his works (major/minor, octatonic, Lydian, Phrygian, "acoustic"): what is interesting is the way in which he sometimes combines them. According to Bartók scholar János Kárpati: “( ... ) although the individual modes may appear as relatively self-contained, independent systems, they do lose their independence... and, producing a new quality, merge (italic M. Z.) into one another" (Kárpati, 1994, 226). 
Polyphony can also be conceived of as a kind of condensation, most obviously in situations found in the works of György Ligeti (1923-2006) written in the 1960s (Atmosphères, or Lontano, for instance). The micro-polyphonic texture of such compositions counts sometimes more than fifty individual lines, and yet these lines somehow "naturally" amalgamate into a mass of sound. The texture collapses upon itself, producing something in the nature of a musical black hole. Such compositions demonstrate the striking level that condensation can reach in music.

Even broader principles of pitch organization, "musical languages" as we (probably inadequately) call them, can be conflated in a single musical piece or a portion thereof.

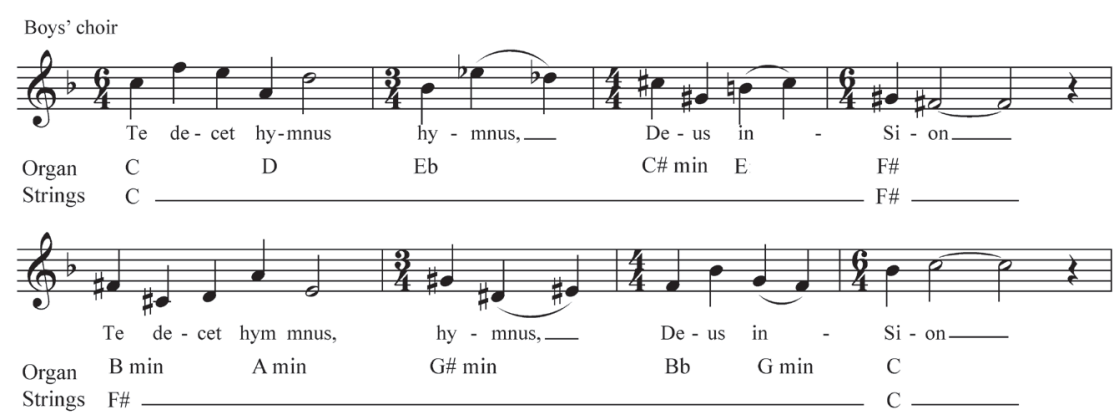

Figure 2. B. Britten, War Requiem, Te decet.

I will illustrate this with a seemingly unassuming example from Benjamin Britten's (1913-1976) War Requiem. The overall profile of the melody, and in particular the absence of overt chromaticism, suggest tonality or modality as the basis for pitch organization; the melody does not project clear tonal-functional relationships, so the modal interpretation would be more plausible. As the pitches follow one another, we soon realize that they do not repeat, and that we are dealing with a twelve-tone row. Well, not exactly. The second and third pitches but last are repetitions of the pitches already stated, and the phrase stops short of completing the full row (the missing tone is $\mathrm{G}$ ); however, on the whole, the idea of a twelve-tone row has already been driven home. This twelve-tone idea is reinforced in the next phrase: it is a transposed inversion of the first and thus conforms to the standard repertoire of dodecaphonic procedures. However, contrary to the original purpose of the twelve-tone method to be a means of obliterating pitch hierarchy, in the present case, since the initial and final pitches are the same tone $\mathrm{C}$, there is at least a hint at pitch centricity. Next, the structure of this example clearly follows the antecedent-consequent pattern of the classical 
tonal syntax. But the stock harmonic pattern $\mathrm{T}-\mathrm{D} \mathrm{D}-\mathrm{T}$ is replaced with the tritone relationship ( $\mathrm{C}$ - F-sharp F-sharp - C). The analogy between tritonal and dominant-tonic relation has been suggested by the Russian musicologist Leo Mazel (Мазель, 1972, 493) in connection with Alexander Scriabin (18711915); it is also found in Bartók and some other composers, but especially Scriabin tends to use it in octatonic contexts, of which there is not as much as a hint in the present example. All this we have inferred from the melody alone. Will the accompanying chords clarify the situation? The string chords seem to reinforce the harmonic profile of a departure from the quasi-tonic to the polar, quasi-dominant chord, and a return to the tonic, whereas the organ provides a touch of bitonality. What conclusions about the pitch organization can we reach based on this account?

A fair conclusion would be that it is extraordinary how all these diverse principles effortlessly blend. Could we even imagine an analogous situation in language? A text written simultaneously in several languages? Later, I will make a few observations concerning condensation in language, but before that, it would be interesting to observe certain analytic strategies and theoretical models of music in light of the primary mechanism of condensation. The clearest example is provided by Schenkerian theory:

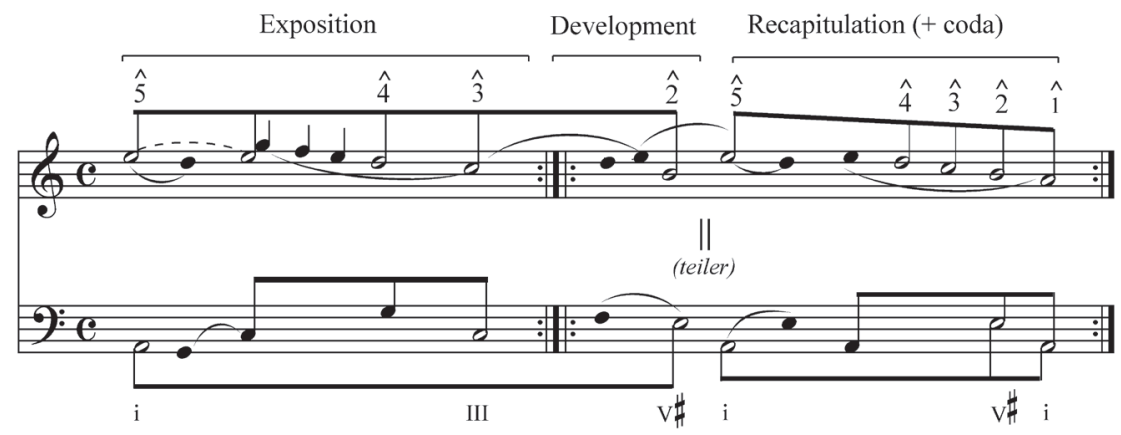

Figure 3. Sonata form, background structure

This Schenkerian graph presents the plausible deep structure of a typical minor-mode sonata form. The first tonic chord condenses all events contained in the first theme and transition. It is not only a manner of graphic presentation: the listener (according to Schenkerians) is expected to somehow conceptualize a single higher-level event as comprising many lower-level ones. Likewise, the elaboration of the mediant (third degree) chord yields, layer by layer, the entire second theme, and so on. Everything occurring within a given area is condensed in a single deep-level event. In general, any theory that postulates "structural 
depth", and approaches music by observing structural layers presupposes condensation, at least by implication. ${ }^{1}$

Now, in the Britten example, we have witnessed a collusion of different principles of pitch organization, but we have said nothing about structural layers. In Schenkerian analysis, we are concerned with structural layers, Schichten, but the uniformity of principles across these layers is something of a dogma. I contend that it is possible to have it both ways: a composition may possess structural depth ${ }^{2}$ but different organizing principles can be distributed across structural layers; in other words, each given set of organizing principles can be attributed to a specific layer. I will present an outline of this idea in the following - shamefully brief - account of a masterpiece of Serbian piano music, Echoes by Vasilije Mokranjac (1923-1984). It is similar to the Britten example in the sense that it is governed by various systems of pitch organization simultaneously. There are certain moments when one might be tempted to apply the rules of functional tonality, and conduct a "Roman numeral analysis". Yet, such an analysis can hardly accommodate tone clusters:
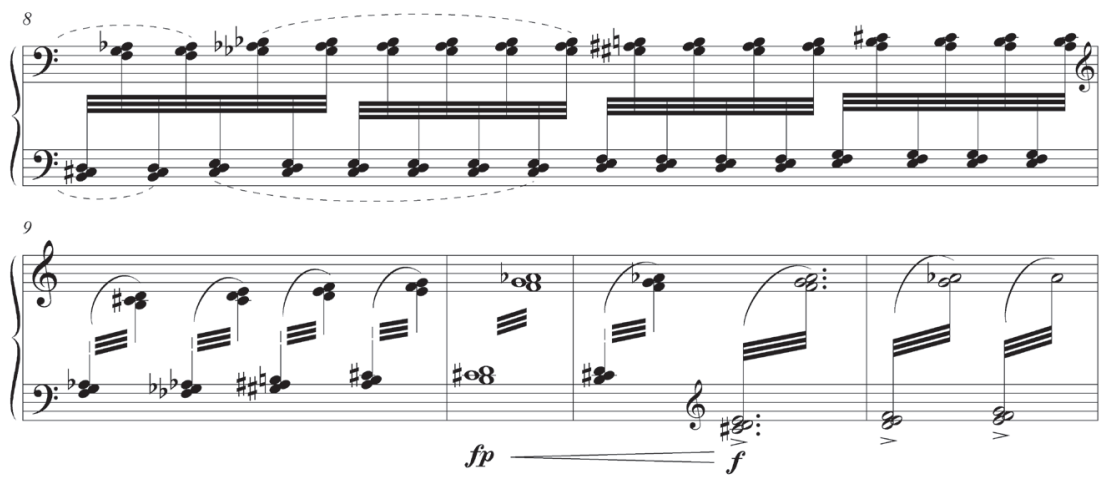

Figure 4. V. Mokranjac, Echoes, VI movement, b. 8-12

1 Among other similar theories I would like to mention Fred Lerdahl's generative theory (Lerdahl, 2001; Lerdahl and Jackendoff, 1996). For a discussion concerning possible analogies with classical narratology (hence narratologically oriented music theories) see Zatkalik and Mihajlović, 2016, 201-203.

2 On this occasion I will not raise the question whether structural layers imply the existence of prolongation, as it would lead us far beyond the scope of this paper.

3 Roman numerals indicate the movement, Arabic ones bar numbers within the given movement. 
The colouring of harmonies with added notes is redolent of impressionism

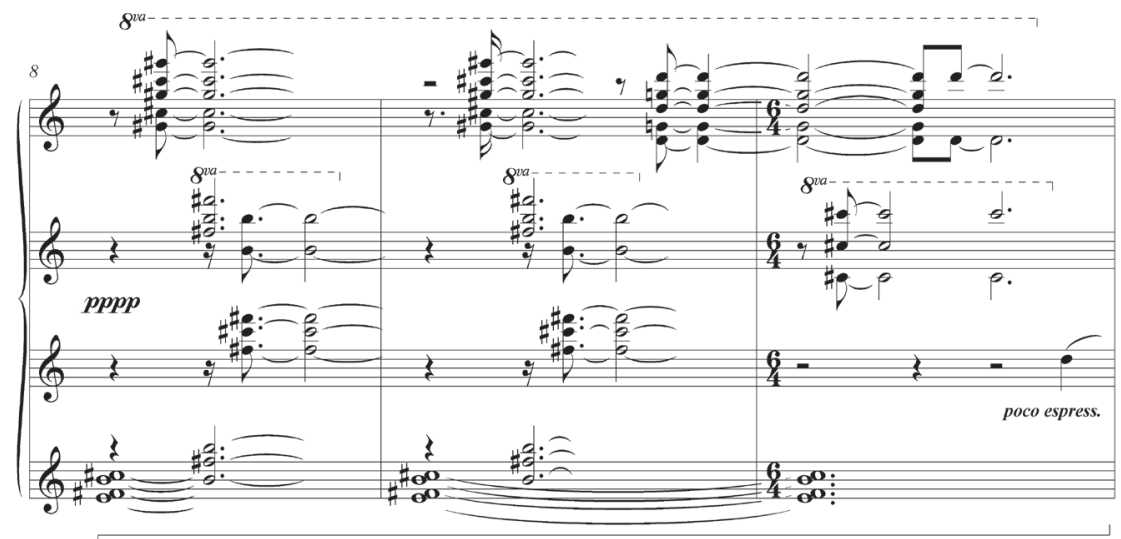

Example 5. V. Mokranjac, I, b. 8-10.

At the same time evocations of ancient past play a significant role, whether mediaeval organum or a quotation from the Byzantine chant.

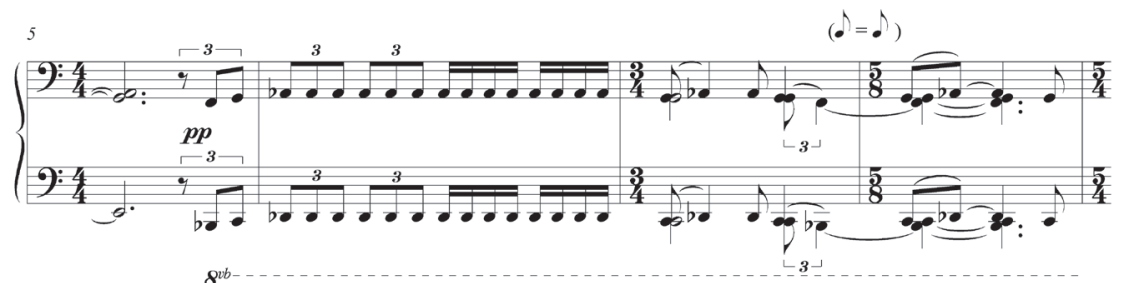

$8^{2 b}$

poco a poco accel.

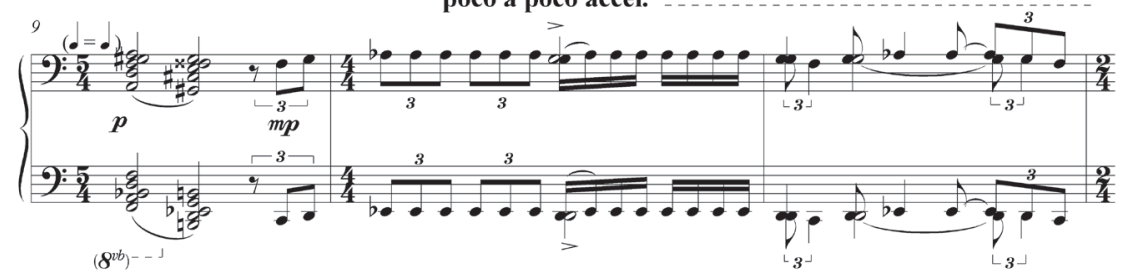

Figure 6a. V. Mokranjac, IV, b. 5-11. 


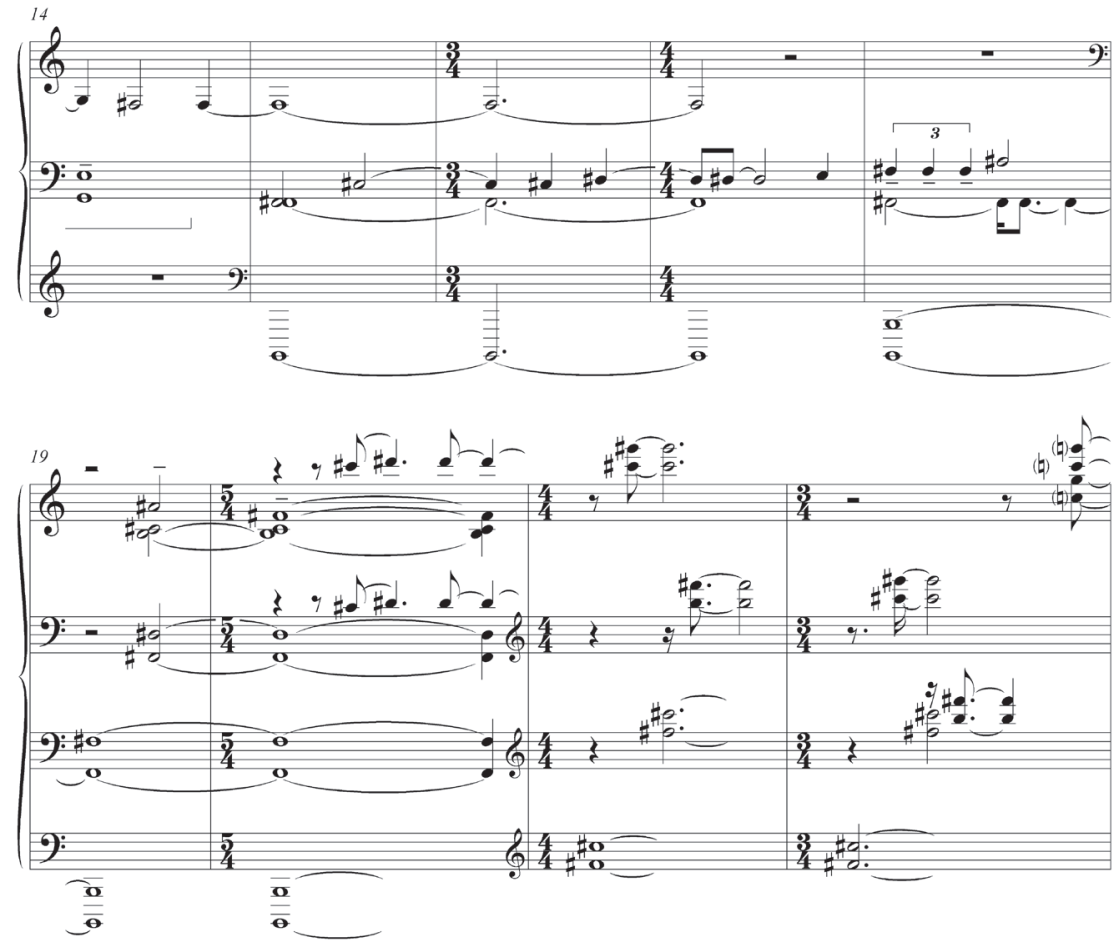

Figure 6b. V. Mokranjac, I, b. 14-22.

Yet, my analysis - of which I can only present conclusions - suggests that at the deepest background there is a tritonal Bassbrechung, a departure from the pitch centre $B$ to $F$ and a return to $B$. It pushes to the surface at a critical structural junction, immediately prior to the return of the Byzantine chant. If my hearing of this music is correct, then we may argue that its very essence is captured at this point of ultimate condensation:

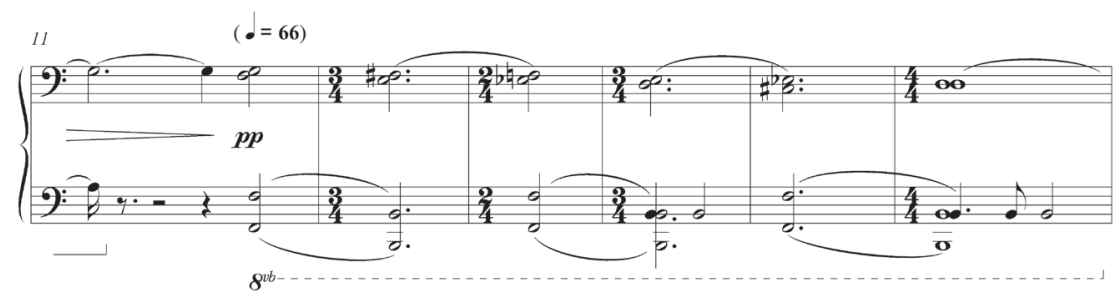




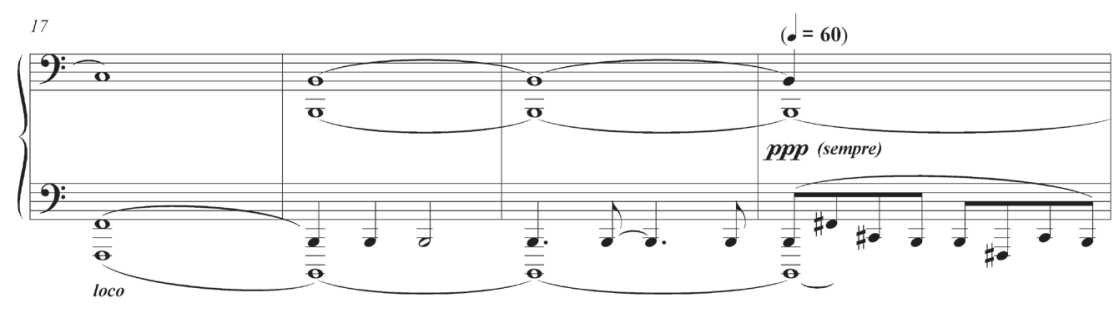

Figure 7. V. Mokranjac, X, b.11-20.

I understand middleground as governed by functional tonality, serving basically to elaborate this fundamental polar relationship. In that sense, it is worth mentioning that the key areas most strongly highlighted are precisely those of $\mathrm{B}$-flat and $\mathrm{C}$, which reinforces the $\mathrm{F}$ as its respective subdominant and dominant. Finally, the surface presents itself as a complex mixture of tonality, modality, local tritonal relationships, coloristic harmonies from the impressionist stock, and sharply dissonant atonal sonorities.

As this paper is drawing to an end, I would like to return to condensation in the verbal domain. We do find it in jokes and puns. On a more "serious" artistic plane, metaphoric language, language rich in connotation could well be invoked as illustration. But the most glaring examples are found in novels by James Joyce (1882-1941). In Ulysses and Finnegans Wake, characters merge into one another: StephenandBloombecome, alternatively,BlephenandStoom; SimonandLeopold merge into Siopold, and Joyce in Finnegan creates an entity called Mamelujo out of the four evangelists. When Shakespeare "crows with a black capon's laugh" (Joyce, 1986, 15: 3828) ${ }^{4}$ we witness the image of Shakespeare conflated with the cock announcing the retreat of the old king Hamlet. We come across fantastic concoctions of words, such as "contransmagnificandjewbangtantiality" (Joyce, 1986, 3: 51), whereas in Finnegan even different languages (more than forty of them!) are fused to produce the unique language of the novel. Images from the past are conflated with present events, achieving temporal condensation that we cannot even begin to discuss now. Observe how unique this is in the domain of words, how bizarre the effects, when compared to quite unobtrusive effortless fusion found in music. Let us put it this way. Artistic creation, or for that matter reception, complex as it is, involves "regression in the service of the ego" as psychoanalyst Ernst Kris called it, that facilitates the emergence of these earlier

4 References from Ulysses are identified by the episode and line numbers in the standard Gabler edition. 
mental states (Kris, 1952; more recently re-actualized in Knafo, 2002). ${ }^{5}$ A work of art - and significantly, music more often than other forms - can produce to socalled "aesthetic peak experience." Research has shown (Panzarella, 1980) that such experience is extremely difficult to verbalize, but it typically involves the feeling of the dissolution of one's boundaries, merging with the work, conflating the inner and outer realities: the "oceanic feeling," an echo of the "original oneness with the mother", in the words of Gilbert Rose (Rose, 2004, 20). By now, it should not be surprising that music, being closest to the archaic mind, is the most common agent of such experience. Indeed, with considerable simplification, we can even grade the arts according to the depth of regression:

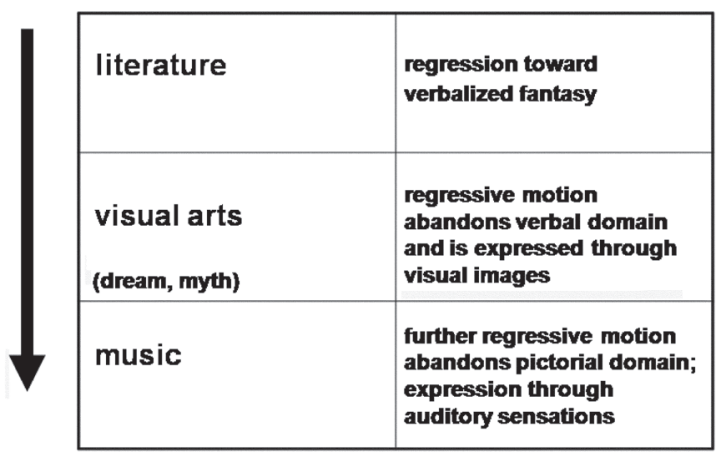

Table 1. Arts according to the depth of regression

Being a product of artistic imagination, a novel or a poem can reach down the regressive path towards the archaic modes of mental functioning, but only so far. Beyond a certain point, it ceases to be a verbal product because language is dominated by the reality-and logic-oriented secondary processes. Through words, says Charlotte Balkányi, "we differentiate the thing from all other presentations; we separate it from its opposite, we distinguish it from similar presentations, and in doing so we exclude the possibility of condensation..." Naming is, therefore, "a basic secondary mechanism” (Balkány, 196, 69). This rhymes well with Susanne Langer's words that "language has a form which requires us to string out our ideas even though their objects rest one within the other... The meanings given through language are successively understood... The linearity of language belies the simultaneity of events" (Langer, 195, 77). Joyce, who probably represents the ultimate regression available to language, is also an author universally acknowledged as extremely musical.

5 I am aware of the fact that the idea of regression does not fare well with a considerable number of contemporary scholars. Yet even those who dismiss it, tend to accept the idea of the fluidity of the boundaries of the self, and fluctuation between primary and secondary states. 
I would like to add one final thought. In the present paper, I have discussed condensation in music chiefly in technical terms: structures, tonalities, and thematic work. There is a great deal more to it. We need to engage more complex and more intriguing questions, to probe still deeper into the innermost recesses of human psyche; to discover how all this reflects on the listener, and on the value of music in our lives. Music can help integrate thought and feeling, achieve, as Gilbert Rose says, inner coherence of underlying identity themes (Rose, 2004, 28). This, too, is a form of condensation, but such a discussion requires another paper, and a great deal more time.

\section{References}

Abell, A., 1955. Talks With Great Composers. New York: Citadel Press.

Balkány, C., 1964. On Verbalization. International Journal of Psycho-Analysis, 45, 64-74.

Freud, S., 1918. From the History of an Infantile Neurosis. Reprint 1955. In: J. Strachey and A. Freud, eds. Standard Edition. Vol. 17. London: Hogarth Press.

Joyce, J., 1986. Ulysses. In: W. Gabler, ed. Harmondsworth: Penguin Books.

Kárpati, J., 1994. Bartók's Chamber Music. Stuyvesant, NY: Pendragon Press.

Knafo, D., 2002. Revisiting Ernst Kris's Concept of Regression in the Service of the Ego in Art. Psychoanalytic Psychology, 19(1), 24-49.

Kris, E., 1952. Psychoanalytic Explorations in Art. New York: International Universities Press.

Langer, S., 1951. Philosophy in a New Key. New York: Mentor Books.

Lerdahl, F., 2001. Tonal Pitch Space. Oxford: Oxford University Press.

Lerdahl, F. and Jackendoff, R., 1996. A Generative Theory of Tonal Music. Cambridge, Massachusetts: MIT Press.

Мазель, А. А., 1972. Проблемы классической гармонии. Москва: Музыка.

Panzarella, R., 1980. The Phenomenology of Aesthetic Peak Experiences. Journal of Humanistic Psychology, 20, 1, 69-85.

Rose, G., 2004. Between Couch and Piano: Psychoanalytic, music, art and neuroscience. London: Routledge.

Stern, D., 1977. The First Relationship: Infant and Mother. London: Harvard University Press.

Stern, D., 1985. The Interpersonal World of the Infant: A View from Psychoanalysis and Development. New York: Basic Books.

Winnicott, D. W., 1953. Transitional object and transitional phenomena. International Journal of Psychoanalysis, 34, 89-97.

Zatkalik, M. and Mihajlović, V., 2016. Prolongacija i strukturni nivoi u posttonalnoj muzici. Banja Luka: Akademija umjetnosti. 
Zatkalik, M. and Kontić, A., 2013. Is There a Wolf Lurking Behind These Notes: The Unconscious Code of Music. In: M. Zatkalik, D. Collins and M. Medić, eds. Histories and Narratives of Music Analysis. Newcastle: Cambridge Scholars Publishing. 628-644.

Zatkalik, M. and Kontić, A., 2015. Psychoanalysis and Music: Discourse about the Ineffable. Muzikologija, 19, 127-146. 